\title{
OXIDE/OXIDE CERAMIC MATRIX COMPOSITE (CMC) EXHAUST MIXER DEVELOPMENT IN THE NASA ENVIRONMENTALLY RESPONSIBLE AVIATION (ERA) PROJECT
}

D. Kiser, N. Bansal, and J. Szelagowski, NASA Glenn Research Center (GRC), Cleveland, OH USA

J. Sokhey, T. Heffernan, J. Clegg, and A. Pierluissi, Rolls-Royce North American Technologies, Inc. (LibertyWorks ${ }^{\circledR}$ /Rolls-Royce Corporation, Indianapolis, IN USA J. Riedell, COI Ceramics, Inc., San Diego, CA USA

S. Atmur, COI Ceramics, Inc., Rocket Center, WV USA

T. Wyen, Air Force Research Laboratory (AFRL)/RQVV, WPAFB, Dayton, OH USA J. Ursic, ZIN Technologies, Inc. (at NASA GRC), Cleveland, OH USA

\section{ASME Turbo Expo 2015}

June 15-19, 2015

Montreal, Canada

GT2015-43593

Research Supported by the NASA Integrated Systems Research Program (ISRP) Environmentally Responsible Aviation (ERA) Project and Rolls-Royce LibertyWorks ${ }^{\circledR}$ 


\section{NASA ERA: Environmentally Responsible Aviation Project}

- Focus on $\mathrm{N}+2$ Timeframe

- Simultaneous reduction of noise, NOx, and fuel burn at vehicle level

- Advance TRL and IRL for key technologies to 5 or 6 by 2015

https://www.aiaa.org/uploadedFiles/About-AIAA/Press-Room/Key_Speeches-Reports-andPresentations/2012/Collier-NASA-AVC-AIAA-GEPC2-2.pdf

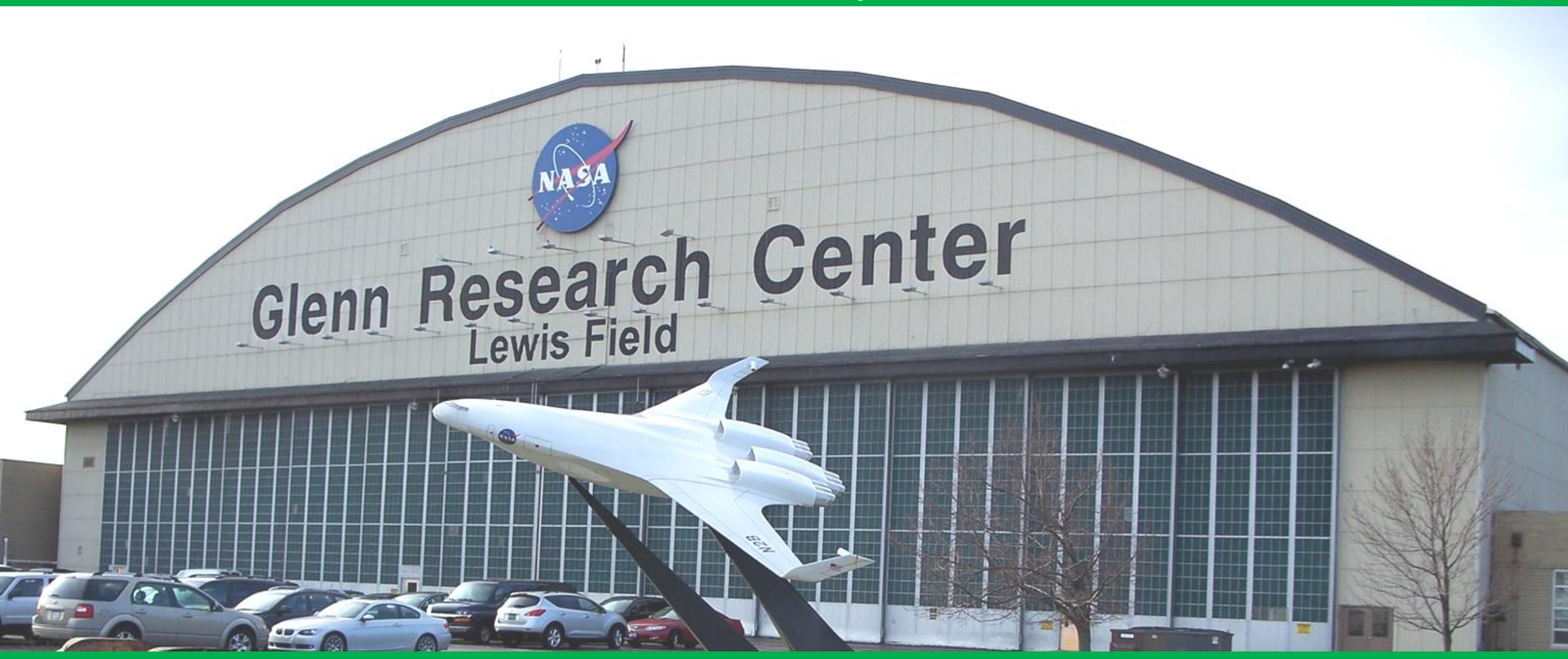

Model of blended wing body (BWB) aircraft in front of the GRC hangar 


\section{Full Scale Oxide/Oxide CMC Mixer Development}

Fabricated by COIC, Inc.
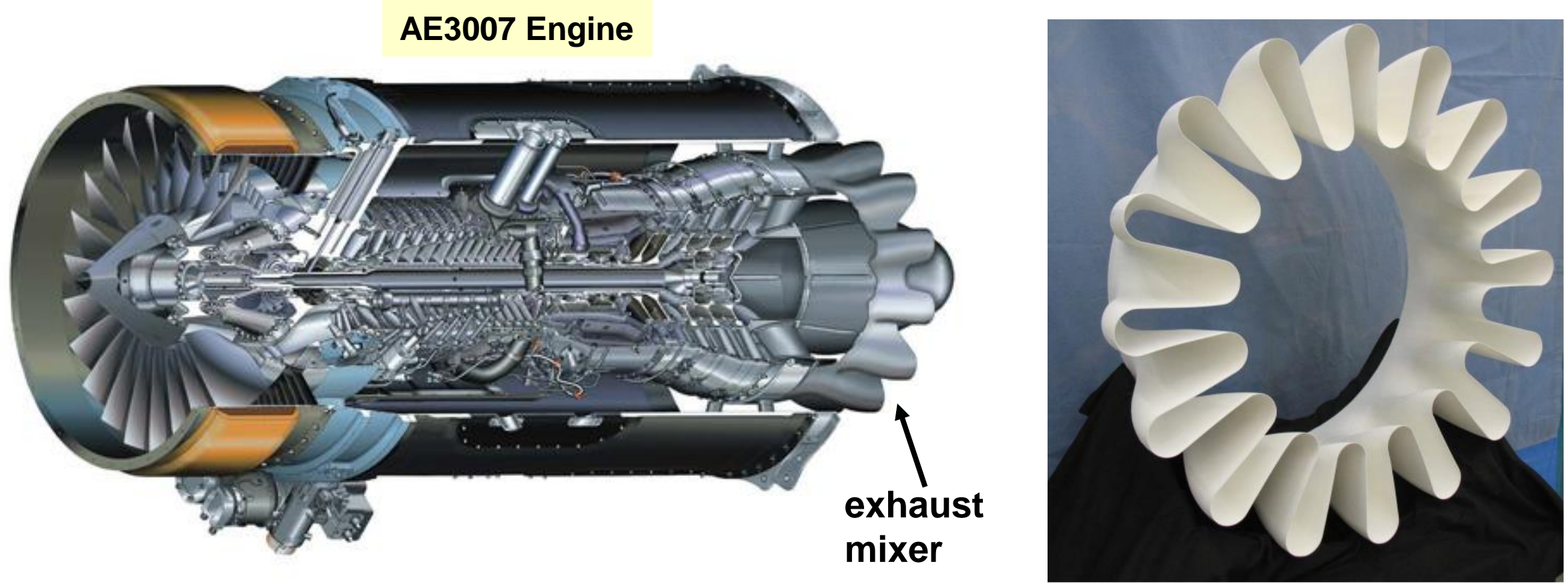

Full Scale CMC Mixer 2014

Objective:

Demonstration of an acceptable level of structural integrity during vibratory testing of a full scale oxide/oxide CMC (ceramic matrix composite) mixer to clear the component for an AE3007 ground test. 


\section{ERA CMC Mixer Development: Technology is Applicable}

to Different Sectors of the Commercial Aircraft Market

Regional and Business Jet Exhaust:
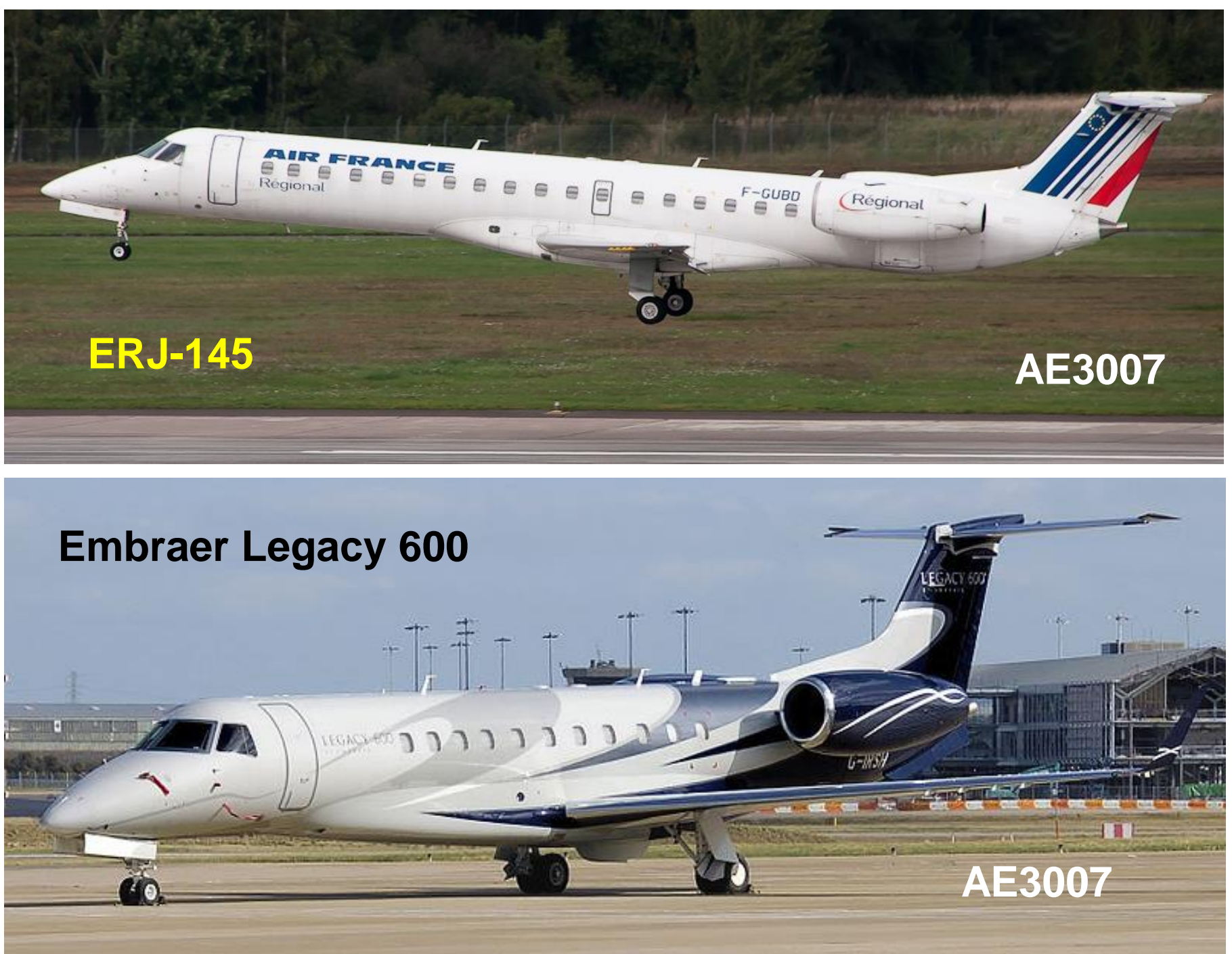


\section{Potential Oxide/Oxide CMC Exhaust Mixer Benefits}

- Weight advantage vs. superalloy component

- High temperature capability desired/required for next generation engines for commercial and military applications

- Manufacturability - ability to fabricate advanced components that can't be made with existing metallic materials

- Sufficient strength/modulus at high temperature to maintain lobe shapes, providing improved performance
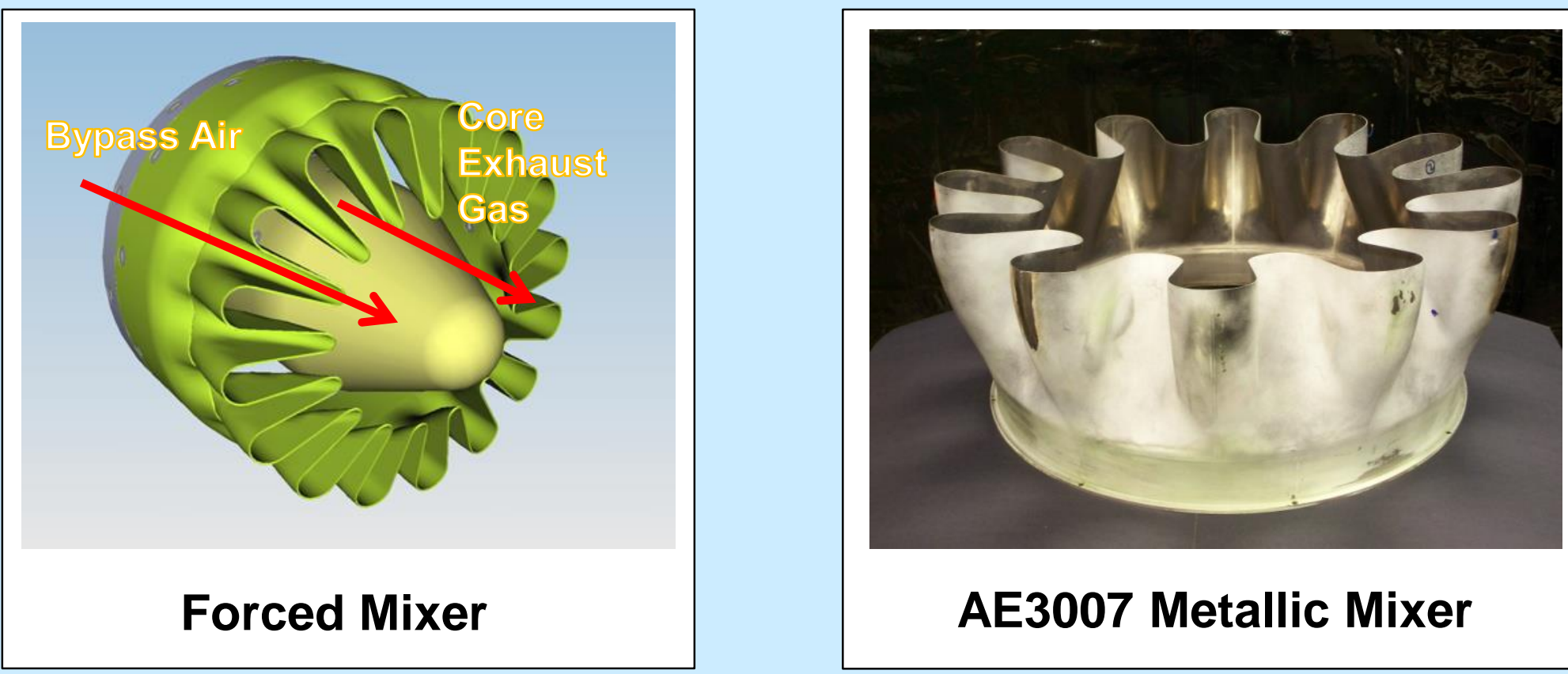

AE3007 Metallic Mixer 


\section{ERA CMC Exhaust Mixer Development}

\section{Approach/Teaming}

- NASA teamed with Rolls-Royce LibertyWorks ${ }^{\circledR}(R R L W)$ and COI Ceramics, Inc. (COIC) to design, fabricate, and vibration test full scale oxide/oxide mixers based on test results of a subscale oxide/oxide mixer designed for true flight environment.

- NASA and RRLW worked together under non-reimbursable NASA SAAs (Space Act Agreements).

- Support Services, LLC was brought into the team to perform engineering/analysis.

- AFRL assisted in test planning and instrumentation, and performed laser vibrometry at NASA GRC and AFRL on full scale CMC mixers as they were excited via impact hammer or vibration testing.

掼 Rolls-Royce

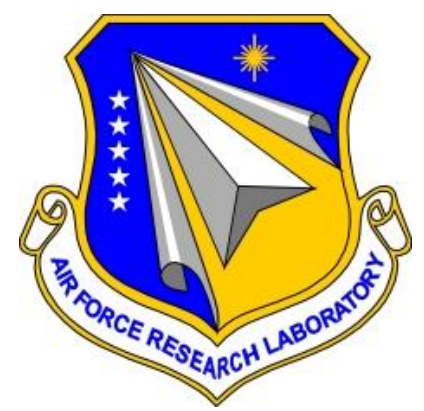

\section{COI Ceramics, Inc.}

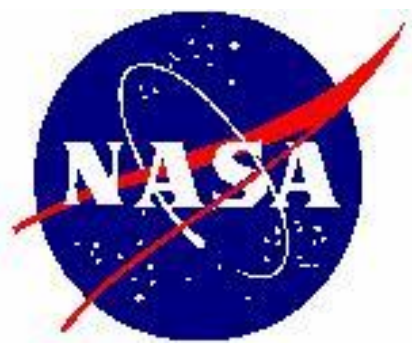

Support Services, LLC.

Engineering \& Analysis 


\section{(N)

\section{Development of an Oxide/Oxide CMC Exhaust Mixer for an AE3007 Jet Engine}

Design and Fabricate Full Scale Ox/Ox Mixers

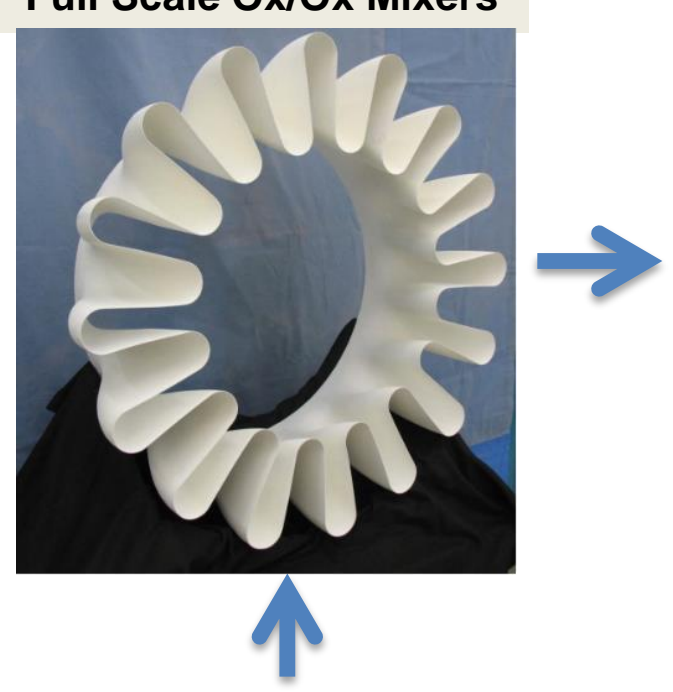

FY11, 12:

Achieved TRL 4

NASA GRC Aero-Acoustic Propulsion Laboratory

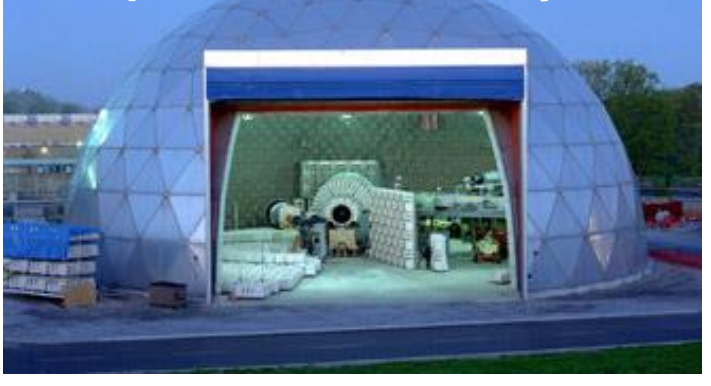

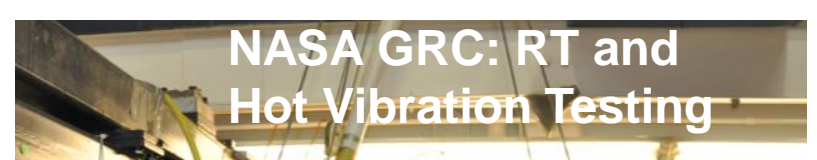

NASA GRC: RT and

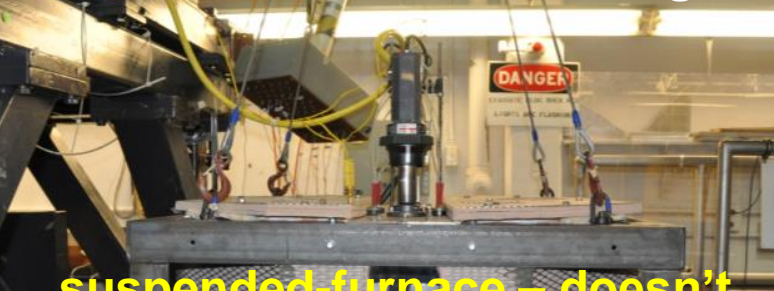

suspeneed furnace doesn contact hesilipila

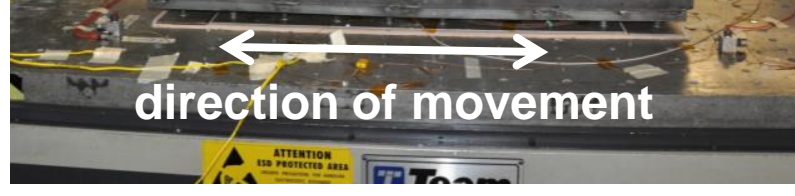

NASA ERA/RRLW Funded

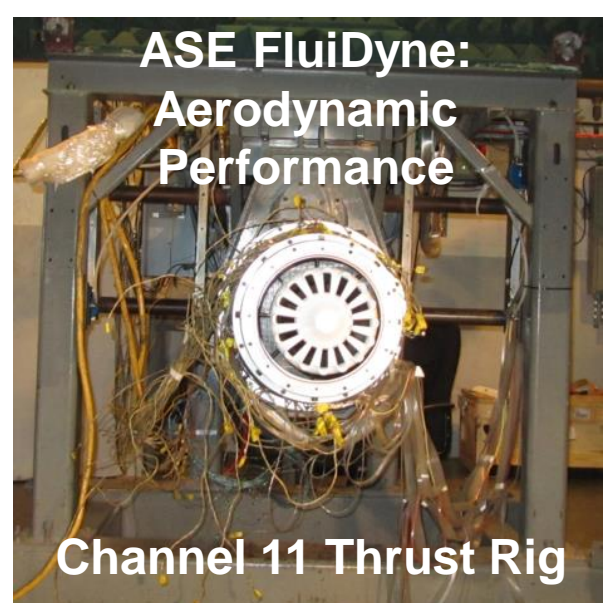

FY12 - FY14:

Achieved $\approx$ TRL 5

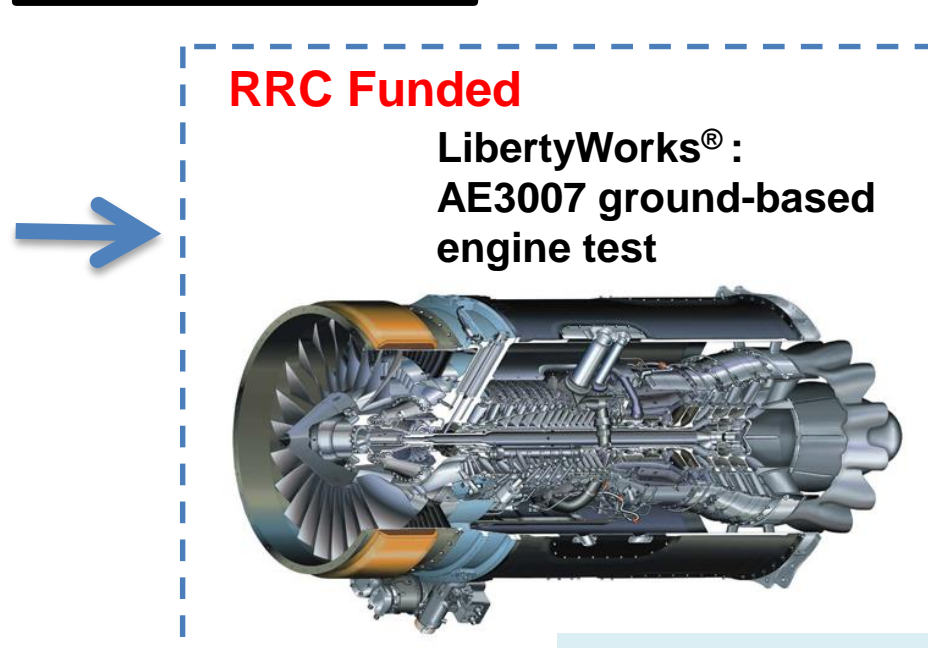

FY15: Goal: Achieve TRL 6

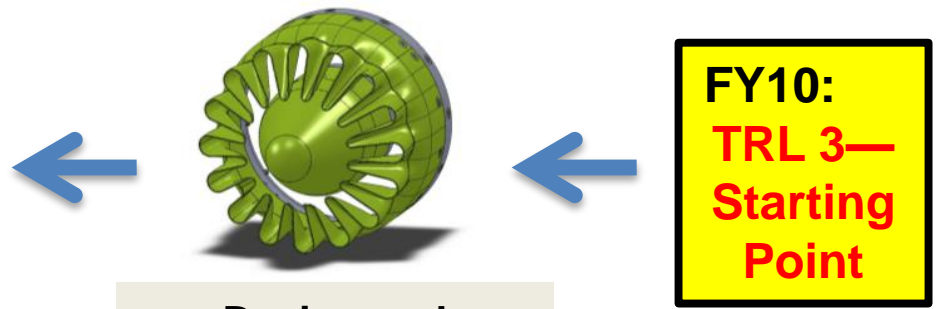

Design and

Fabricate Subscale Ox/Ox Mixer 


\section{Design of Full Scale Oxide/Oxide CMC Exhaust Mixer}

Thermal / Structural Analysis and Resonance / Natural Frequency Analysis Performed on Full Scale CMC Mixer and Attachment Flange Assembly

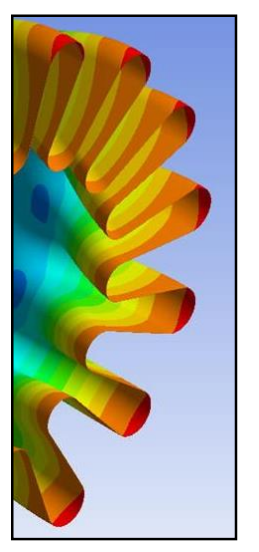

- CMC thermal / mechanical properties for AS-N610 ${ }^{\mathrm{TM}}$ were provided by COIC.

- Boundary condition data (operating conditions that a mixer for a turbofan engine would experience) were defined by RRLW.

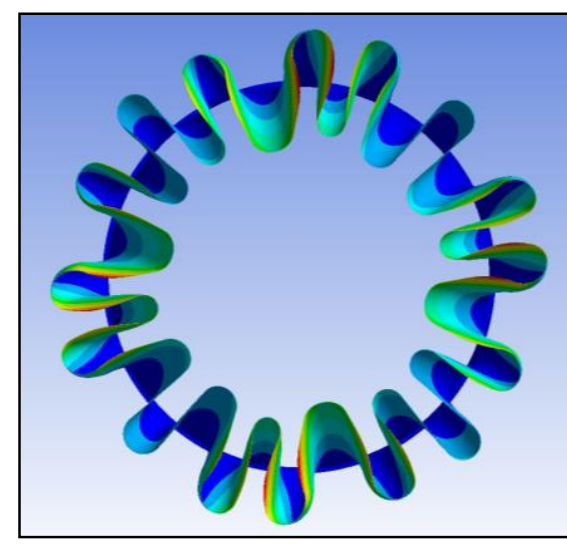

- Design Support, Engineering, and Analysis by Support Services, LLC.

- Assembly was designed to attach to an AE3007 aircraft engine. Fabrication issues were taken into account as part of the design.

$\rightarrow$ - CTE mismatch between the Ox/Ox CMC mixer and the metallic attachment flange is one of the primary challenges-due to the size of the component.

- Design reduced structural and thermal stresses to acceptable levels (for takeoff conditions). Retention of shape during operation was also assessed.

$\rightarrow$ - Analysis of assembly identified critical frequencies to vibration test.

- Component Design Review at RRLW. 


\section{Vibration Testing of Full Scale CMC Mixer GRC Structural Dynamics Lab}

\section{Full Scale CMC Mixer 2013}

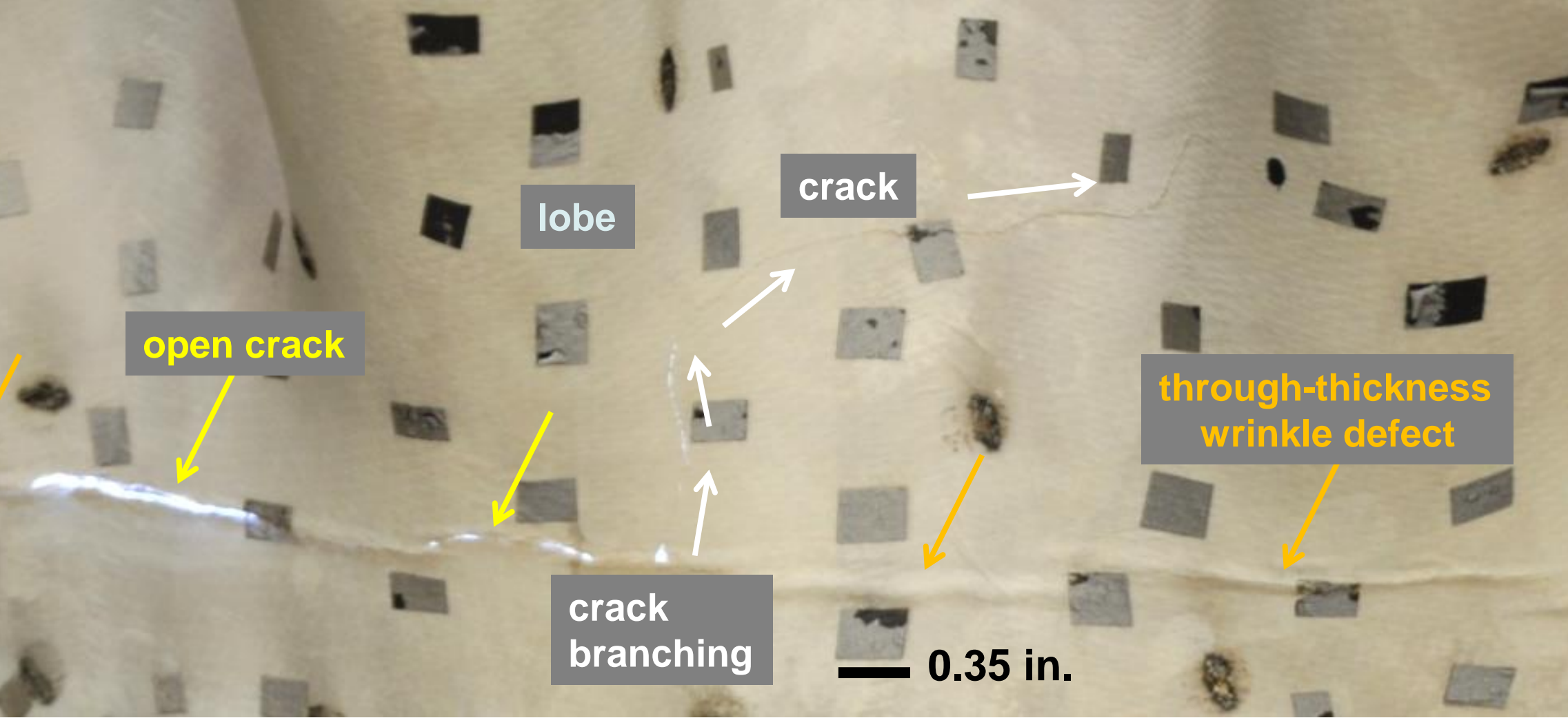

Failure of "Full Scale CMC Mixer 2013" During Vibration Testing in 2013

- Crack formation and propagation associated with circumferential wrinkle processing defect.

- Wrinkle defect resulted from fabrication of full scale component using prototype tooling.

- Crack gradually grew during the various vibration test runs, propagating along the defect until branching out toward the lobes. Testing was discontinued prior to completing the test matrix.

- Cracks did not form elsewhere in the mixer (only where the main wrinkle defect was located). 10 


\section{Full Scale Ox/Ox CMC Mixer 2014}

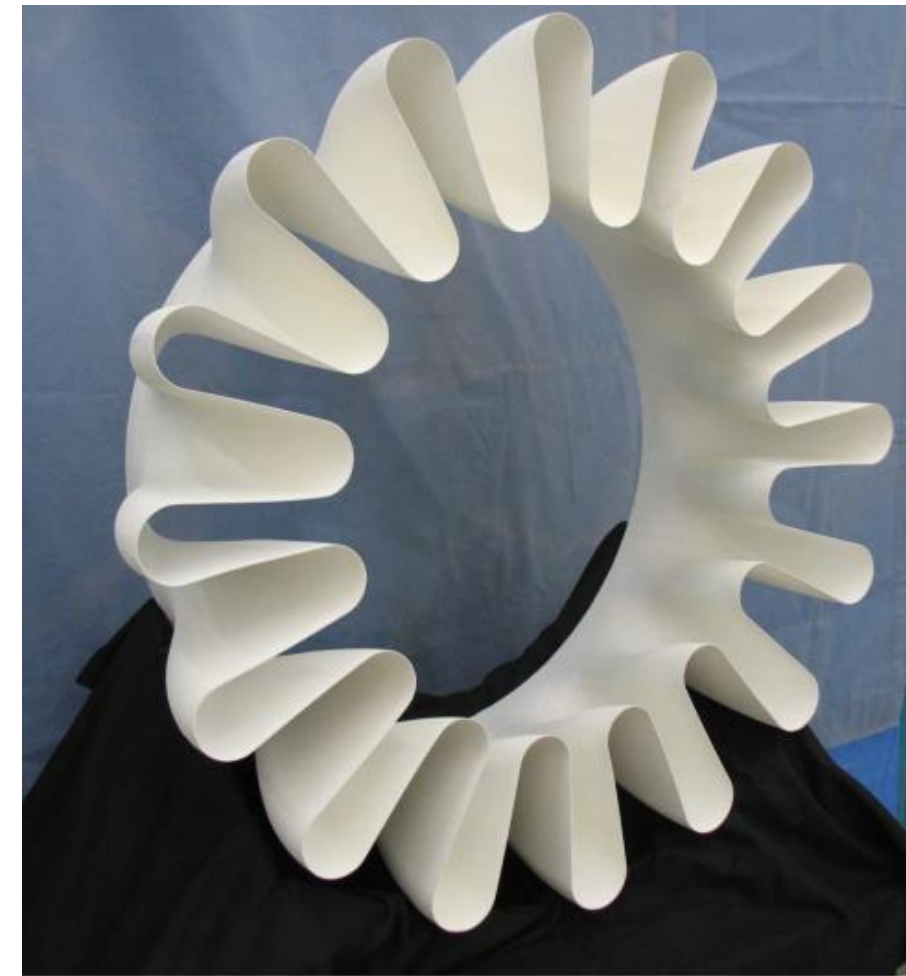

16 Lobe CMC Mixer 2014

Fabricated by COIC, Inc.
- GRC received a second full scale oxide/oxide CMC mixer in May 2014.

- This image shows the mixer prior to the machining of the holes for the attachment ring bolts.

- The "body" of the mixer beneath the lobes showed significant improvement in comparison to the mixer fabricated in 2013.

- CMC Mixer 2014 is more symmetrical and has no through-thickness wrinkle defects (the critical flaw observed in the previous mixer (CMC Mixer 2013)).

- The lobes are more symmetrical, with less variation in the tip-to-tip distances. Some lobe wall thickness variations and outer surface wrinkles were observed. 


\section{Full Scale ERA Ox/Ox CMC Mixer 2014}

Natural Frequency Testing

- Natural Frequency (Mode Generation) Testing was performed at AFRL, using their 3D laser vibrometry system to characterize the modes from 10-350 $\mathrm{Hz}$.

- The natural frequency modes were generated using a small, instrumented, rubber-tipped hammer.

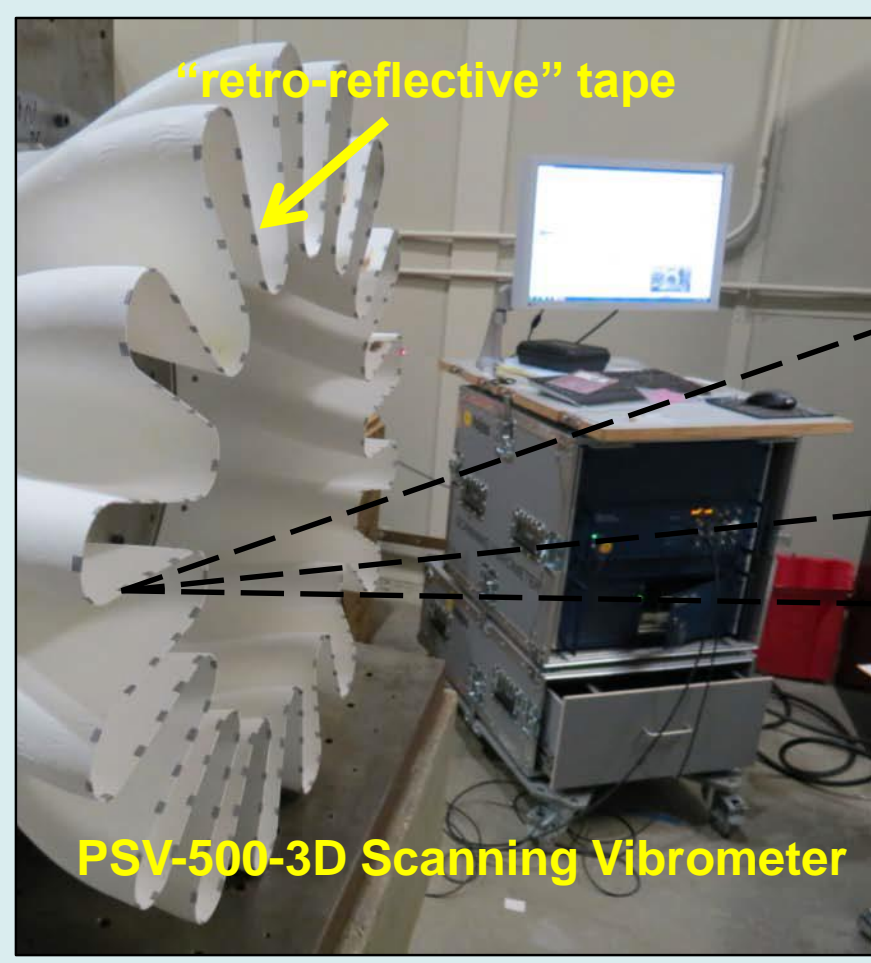

Laser vibrometry was performed on CMC Mixer 2014 while it was attached to the mount plate

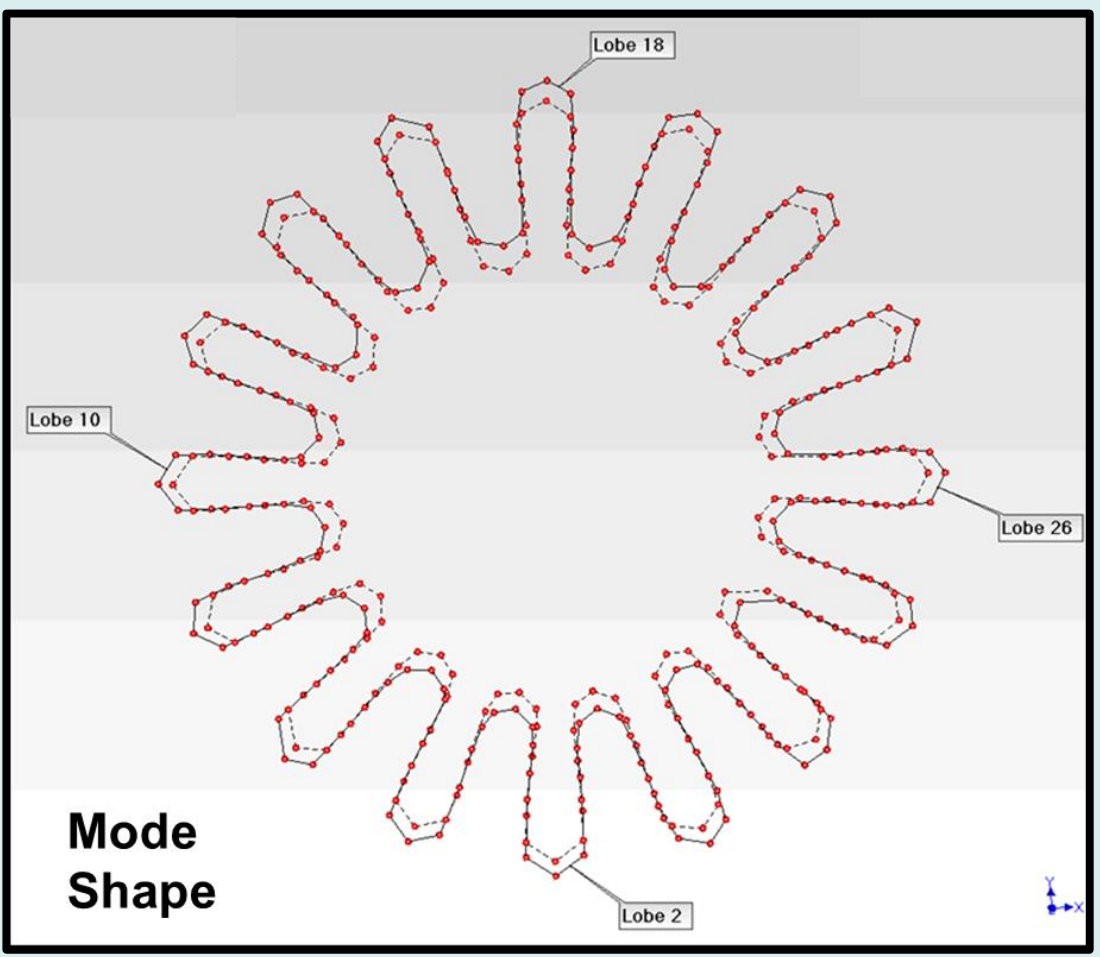

Example--CMC Mixer 2013: Software-generated animation of mode shape derived from laser vibrometry measurements 


\section{Vibration Testing of Full Scale Ox/Ox CMC Mixer}

Instrumentation

- 26 high temperature strain gages were mounted on $\approx$ Lobes 29,31 , and 1 at AFRL.

- Fine Multifilar lead wires were soldered to the strain gage jumper wires $\mathbf{w} /$ silver solder.

- Four thermocouples were attached to the component using copper silicone RTV.

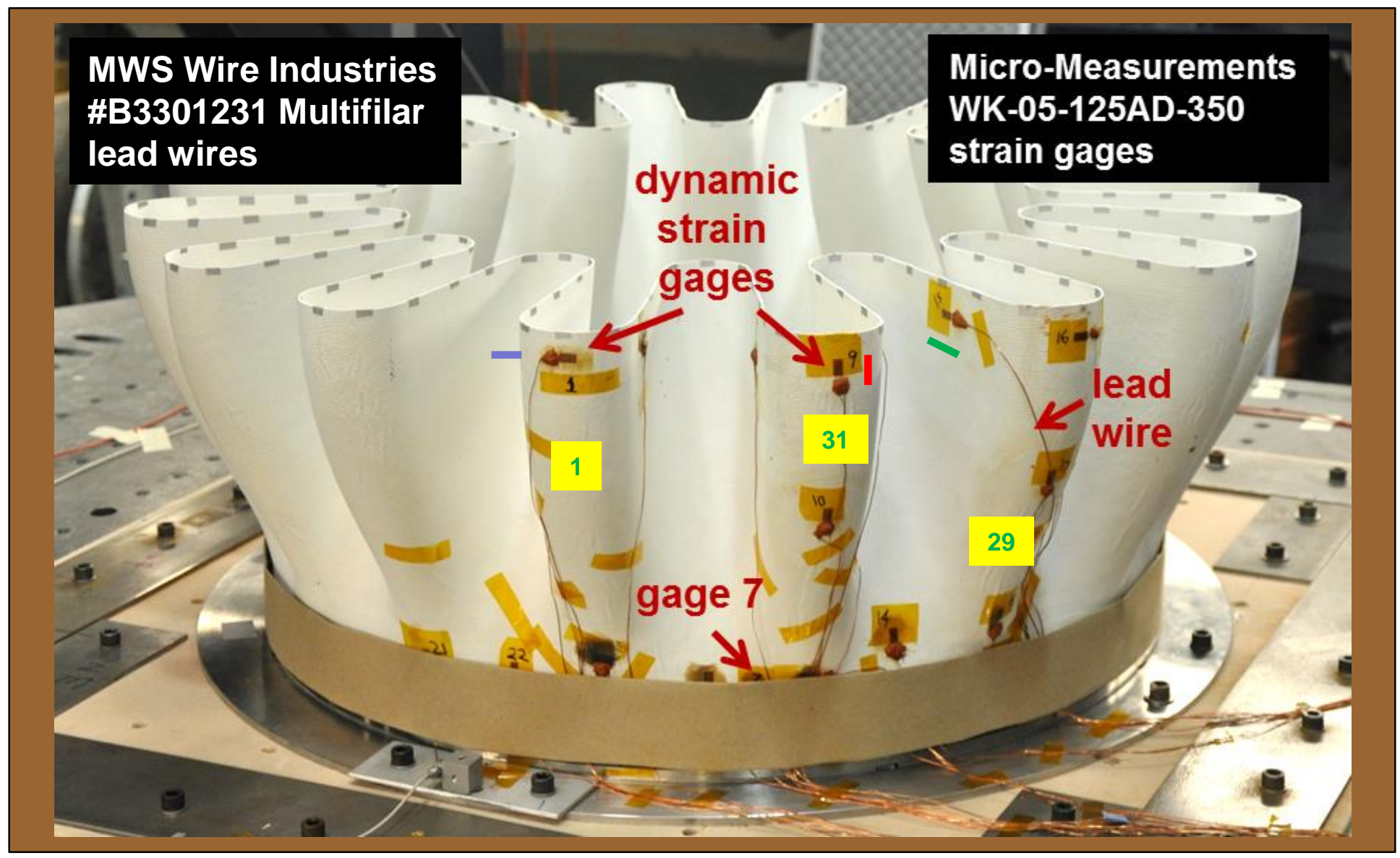

Strain gages oriented in circumferential $(-)$, axial $(-)$, and radial $(-)$ directions 


\section{Vibration Testing of Full Scale CMC Mixer 2014 GRC Structural Dynamics Lab}

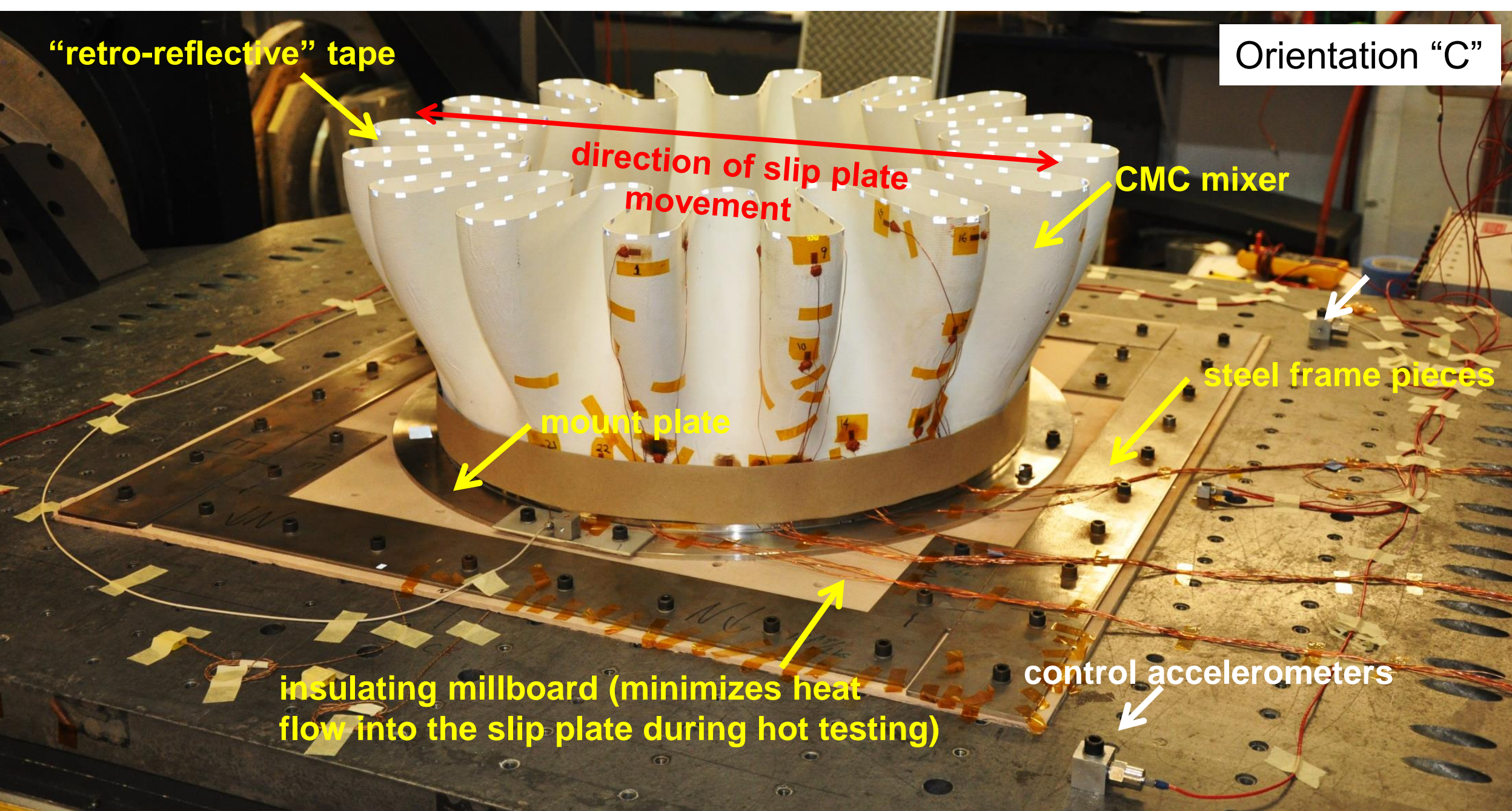

Test Set Up: Full Scale ERA Ox/Ox CMC Mixer 2014 Mounted on Slip Plate

- Attachment ring, which is bolted to both the mount plate and mixer, has been covered

- Retro-reflective tape used during laser vibrometry characterization of modes 


\section{Vibration Testing of Full Scale CMC Mixer Strain Survey Testing / Sine Sweeps}

High Level Sinusoidal Inches Per Second (IPS ${ }_{\text {rms }}$ ) Velocity Sweep Testing (Acceleration Levels Expressed in g's)

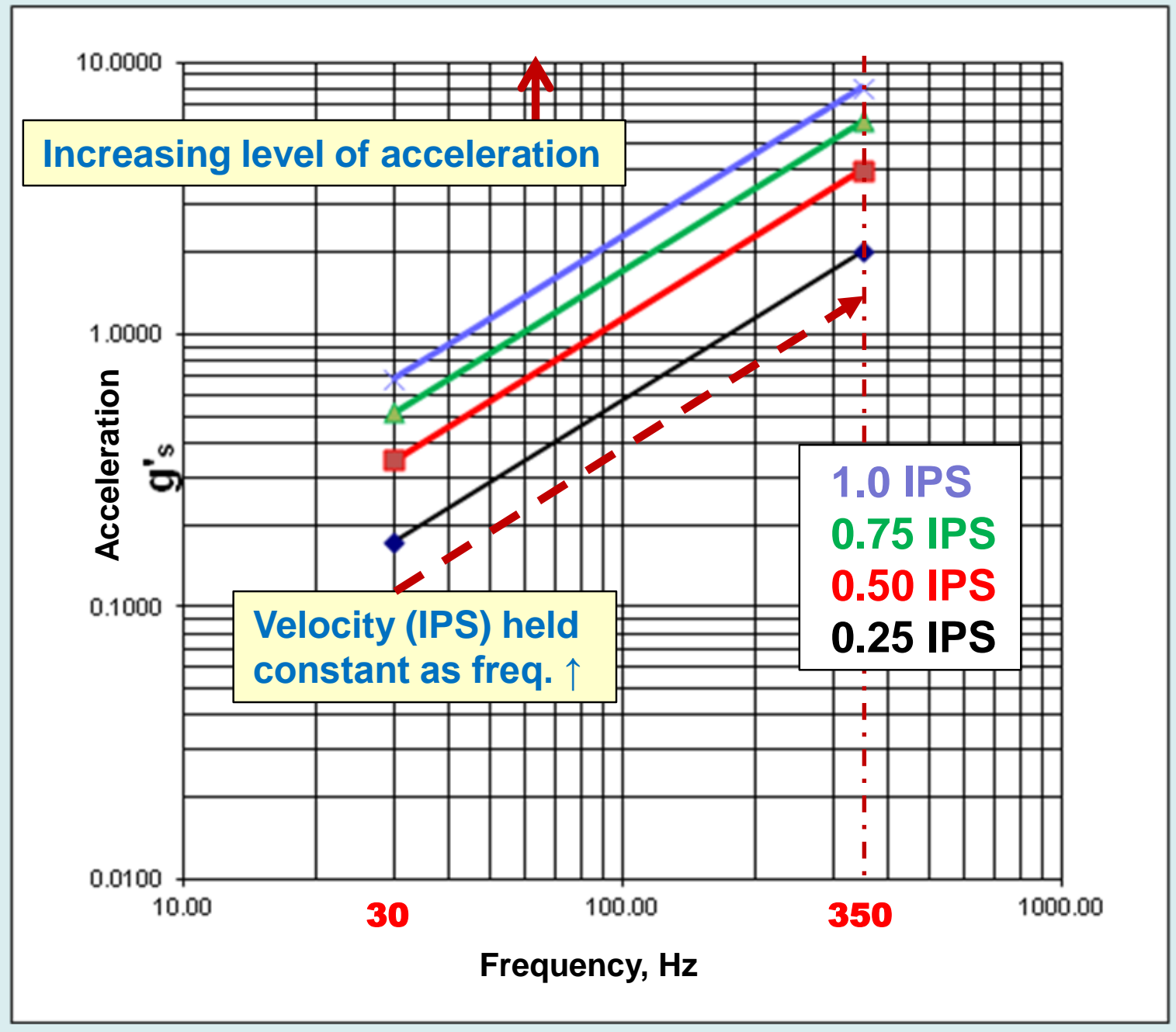

- Sine sweep testing was used to interrogate the structural integrity of the mixer and to detect processing-related defects.

- Excitation at one freq. at a time, with frequency increasing over time from 30-350 Hz.

- As the acceleration level increases at any particular frequency, the potential for damage increases.

- Identify mode producing the highest vibratory stress (and strain). 


\section{Ox/Ox CMC Mixer Initially Vibration Tested at 0.25 and 0.50 IPS $_{\mathrm{rms}}$}

in Three Orientations to Identify the Maximum Strain Observed

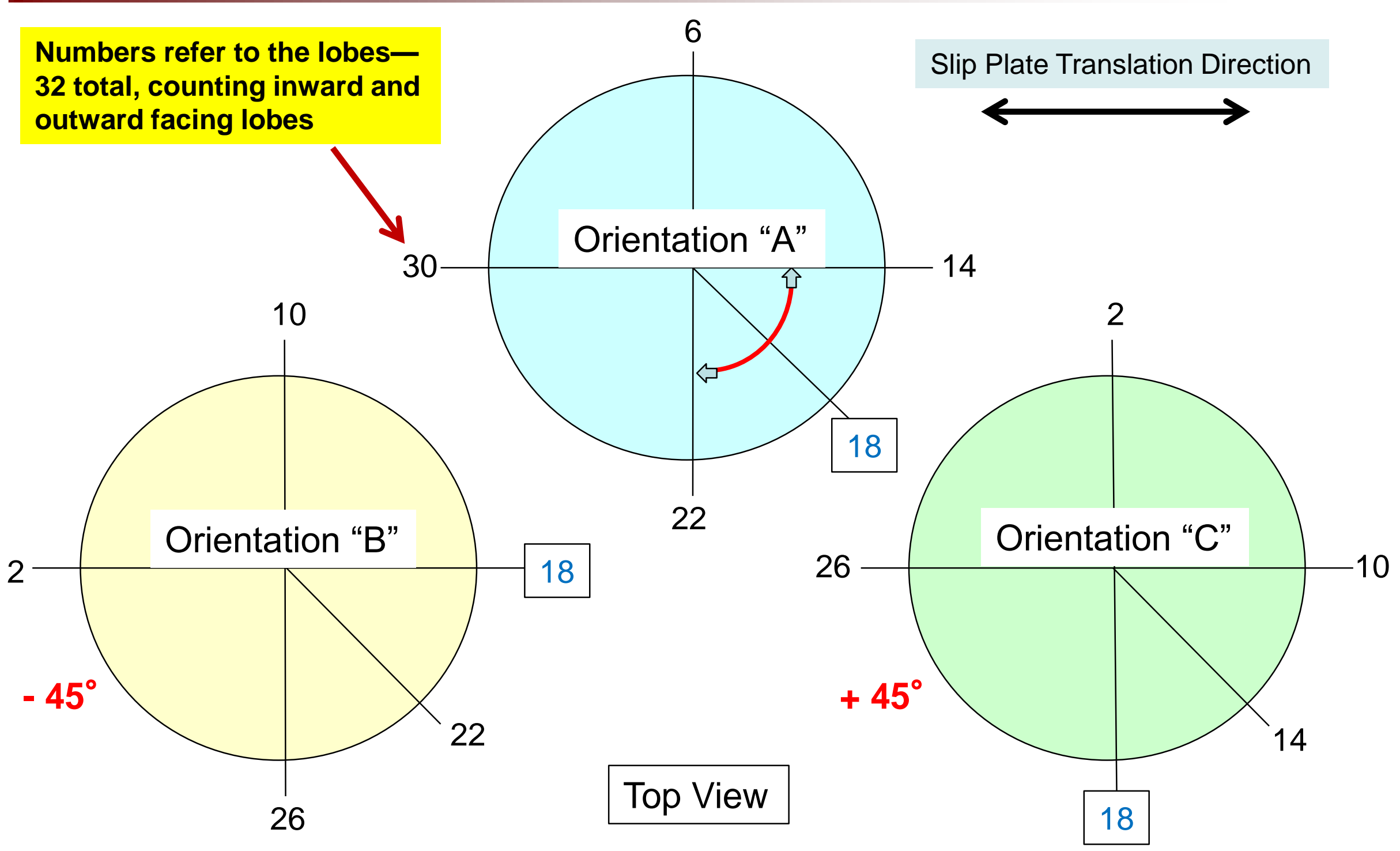

- Strain gages were primarily mounted on 3 adjacent outward facing lobes $(29,31,1)$

- Orientation " $\mathrm{B}$ " was used for the remaining testing 


\section{Vibration Testing of Full Scale CMC Mixer}

\section{Vibration Dwell Tests}

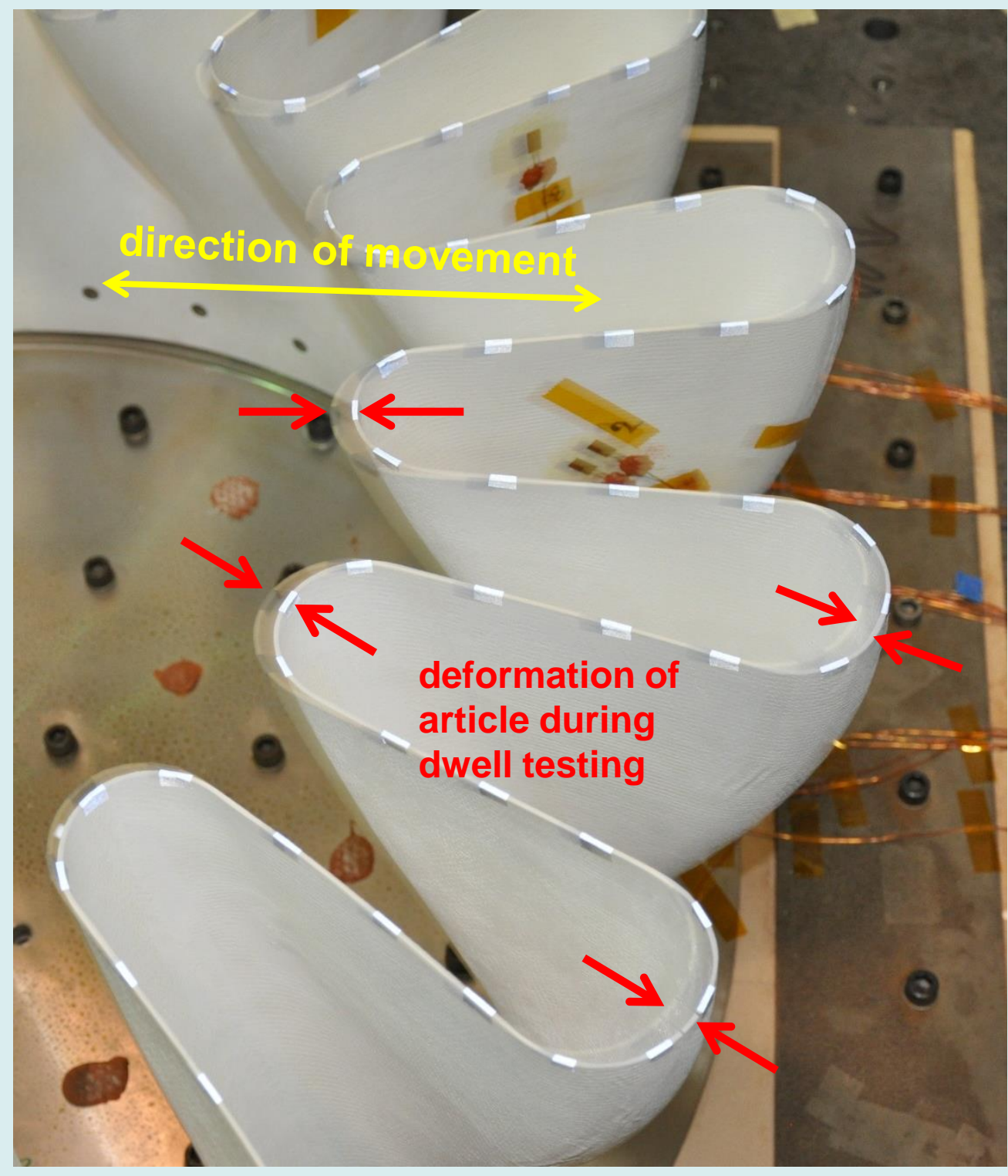

- Vibration dwell tests were performed as fatigue tests that interrogate the structural integrity of the mixer at a specific frequency (mode) with testing performed at a constant velocity.

- The maximum strain gage reading was monitored during dwell tests at a specific frequency in order to maintain a slip plate velocity that provided the desired level of maximum strain within the test article. 


\section{Hot Vibration Testing of Full Scale CMC Mixer GRC Structural Dynamics Lab - Suspended Furnace}

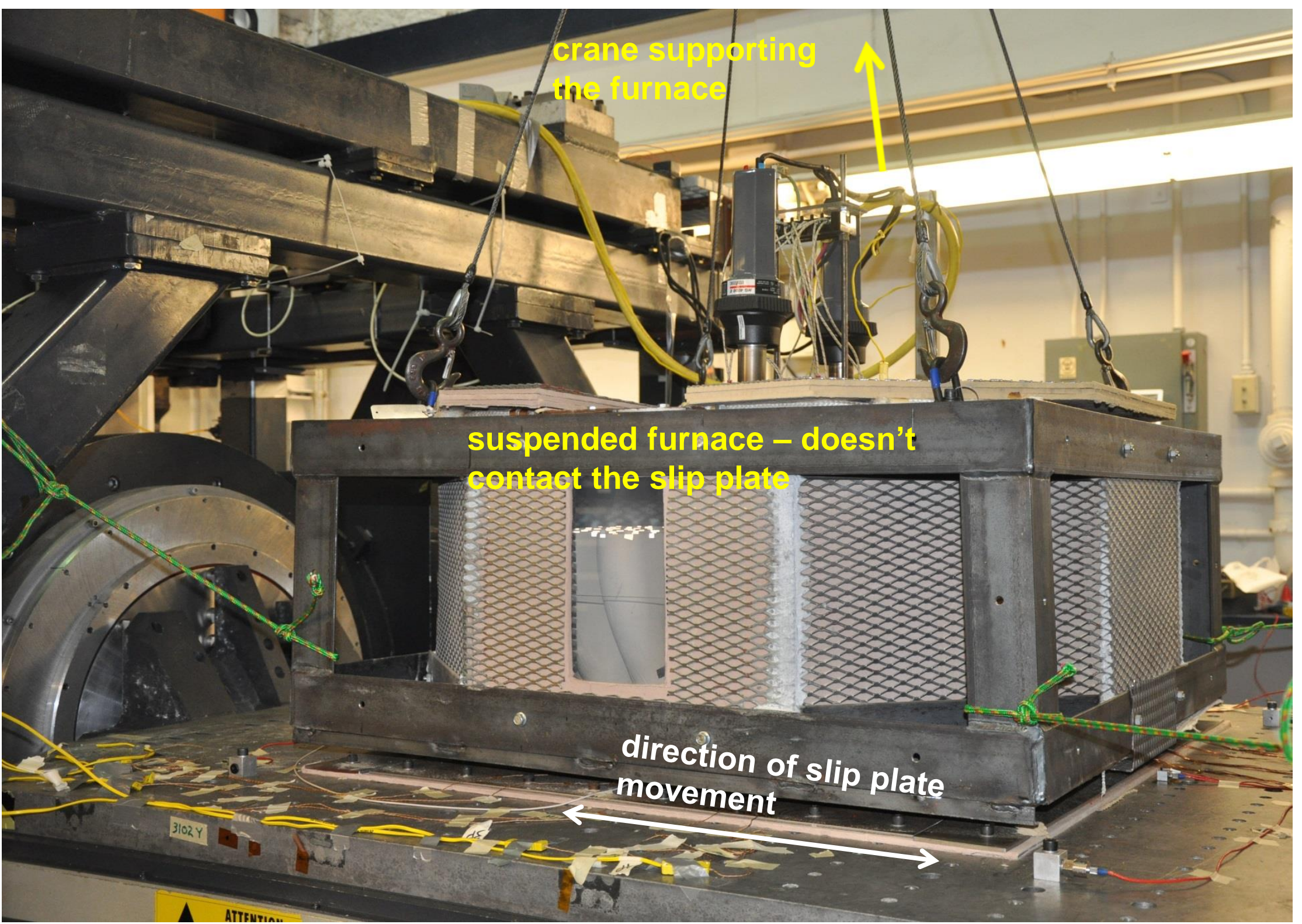




\section{Hot Vibration Testing of Full Scale CMC Mixer}

GRC Structural Dynamics Lab - Suspended Furnace

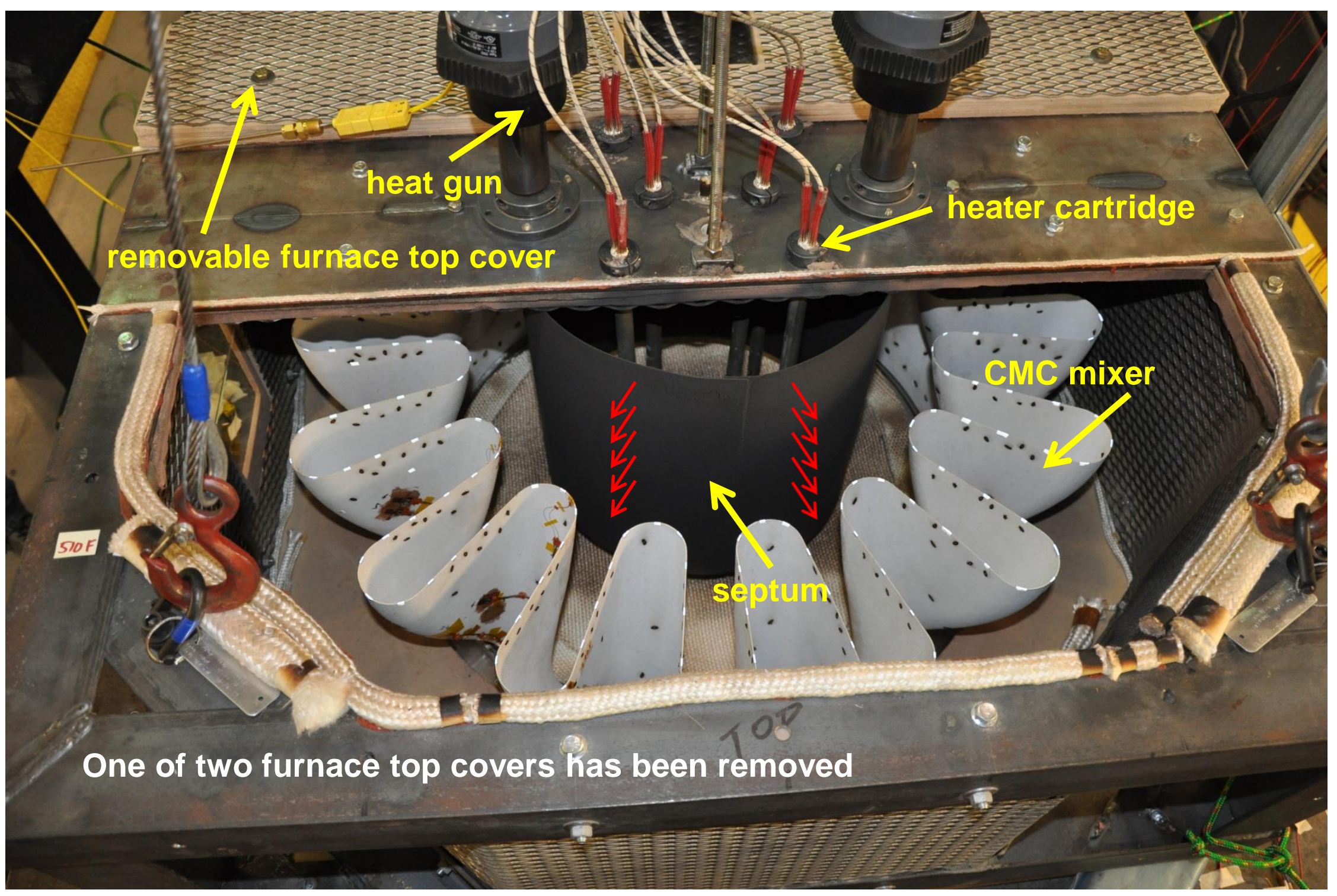

Radiative and Convective Heating of the Mixer's Inner Surface 


\section{Full Scale Ox/Ox CMC Mixer 2014 Overview of Vibration Tests Performed}

1) Room Temperature Vibratory Tests

- $0.25,0.50,0.75,1.00$ inches $/ \mathrm{sec}_{\mathrm{rms}}$ sine sweeps to simulate start to max. speed acceleration

- Two 1 million cycle dwells at $2^{\text {nd }}$ natural frequency and a specified maximum microstrain level

- One million cycles completed before and after the hot vibratory testing

- No significant anomalies noted

2) $700^{\circ} \mathrm{F}$ Vibratory Tests

- 0.50, 1.00 inches $/ \mathrm{sec}_{\text {rms }}$ sine sweeps

- 100,000 cycle dwell at $2^{\text {nd }}$ natural frequency and a specified maximum microstrain level

- Test set-up limited the length of the dwell test

- No significant anomalies noted 


\section{Vibration Testing of Full Scale CMC Mixer GRC Structural Dynamics Lab}

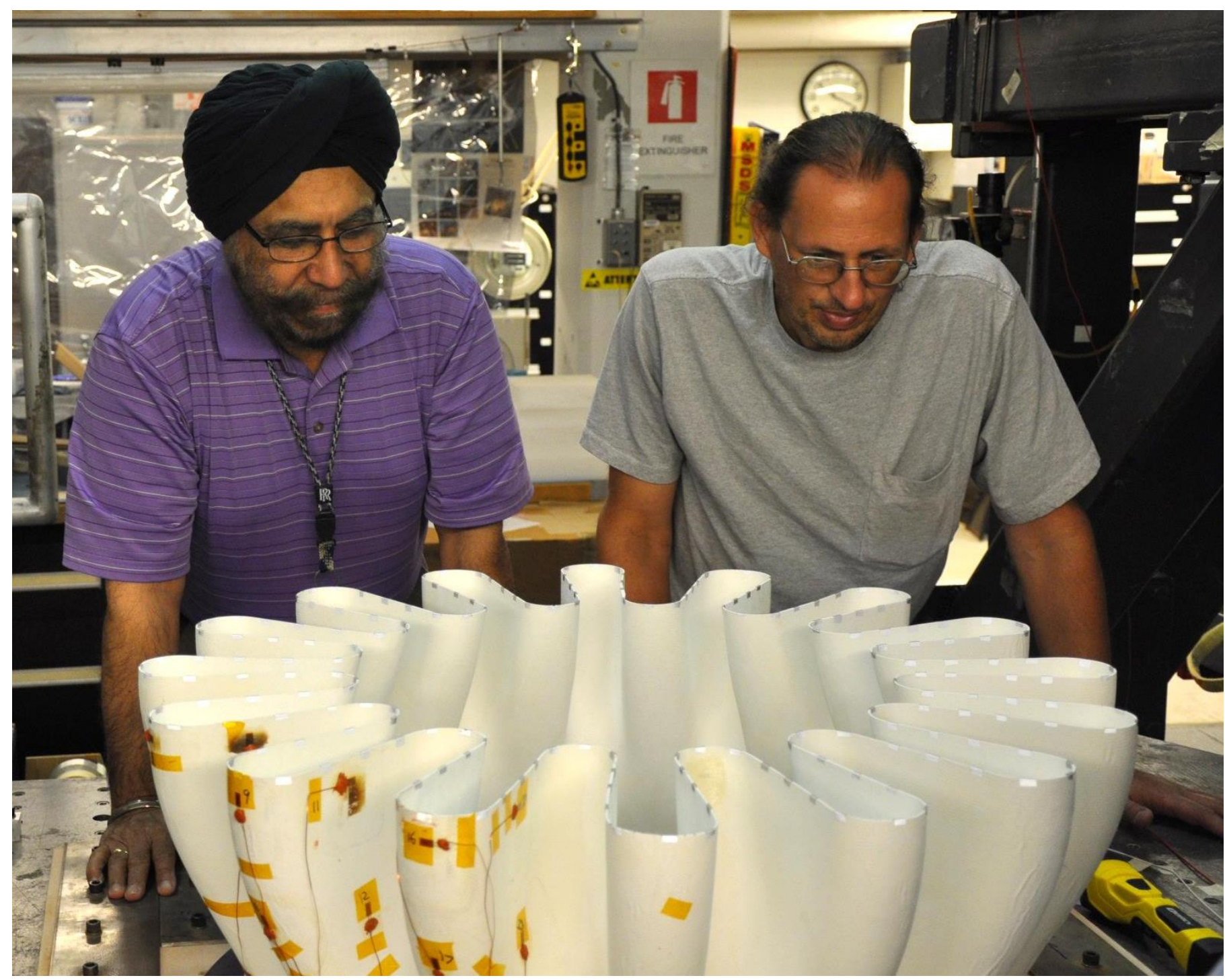

Visual Inspection of the Full Scale ERA Ox/Ox CMC Mixer 2014 
- The Vibratory Test Matrix was defined by LibertyWorks ${ }^{\circledR}$ as a screening study to clear the CMC mixer for a TRL 6 ground-based engine test.

- Processing and design modifications were implemented by COI Ceramics, Inc. to address defects observed in the Ox/Ox CMC mixer that we tested in 2013. This led to improved component quality/symmetry and durability in the 2014 CMC mixer.

- Modal frequency testing was performed to assess the natural frequencies of the full scale CMC mixer from $10-350 \mathrm{~Hz}$. 3D laser vibrometry was used to identify the mixer mode shapes and modal frequencies.

- Sine sweeps were performed from $30-350 \mathrm{~Hz}$ at RT, 600\%F, and 700\% F, at velocities ranging from 0.25 to 1.0 Inches Per Second (IPS ${ }_{\mathrm{rms}}$ ).

- Dwells were performed at RT and $700^{\circ} \mathrm{F}$, at the $2^{\text {nd }}$ natural frequency and a specified microstrain level. That frequency was selected because it is where we observed the highest strains during preliminary testing.

- Two 1 million cycle dwells were performed at RT and one 100,000 cycle dwell was performed at 700 - $F$.

- Through-thickness cracks did not form in the mixer. Three minor defects were observed following testing. 


\section{Full Scale ERA Ox/Ox CMC Mixer 2014: Conclusions}

Conclusions:

- CMC Mixer 2014 was successfully vibration tested, exhibiting good durability during dwell testing.

- While deformation of the lobes was easily observed during the dwell tests, the strength and flexibility of the component kept it from experiencing significant damage.

- TRL was increased from 3 to $\approx 5$ during this project.

- The current test set-up (hardware) limits the length of vibration tests performed at elevated temperature. However, modifications have been identified that would allow hot vibration testing for longer periods of time.

- Longer exposure to $700^{\circ} \mathrm{F}$ could lead to increased degradation of the strain gages. 


\section{Next Step:}

- The component was further evaluated at Rolls-Royce and it is now being prepared for an AE3007 ground test at Rolls-Royce in Indianapolis, IN. 


\section{Acknowledgments-CMC Mixer Subtask}

Testing, Analysis, Project Management, Technical Input, Fabrication, Instrumentation...

- S. Haeske, Support Services, LLC (Allendale, MI USA) (deceased)

- J. Lane and M. Blose, Rolls-Royce Corporation (Indianapolis, IN USA)

- K. Suder, D. Van Zante, J. Grady, and J. Heidmann, NASA GRC (Cleveland, OH USA)

- F. Collier, NASA LaRC (Hampton, VA USA)

- D. Pulice, G. Buchar, M. Woidke, D. Pottinger, T. Jones, and T. Ferrier, NASA GRC (Cleveland, OH USA)

- R. Pawlik, U. Toledo-at GRC (Cleveland, OH USA)

- F. Bremenour, Gilcrest-at GRC (Cleveland, OH USA)

- W. Brown, Sierra Lobo, Inc.-at GRC (Cleveland, OH USA)

- G. Polansky, Booz Allen Hamilton-at GRC (Cleveland, OH USA)

- M. Petervary, The Boeing Company (Huntington Beach, CA USA)

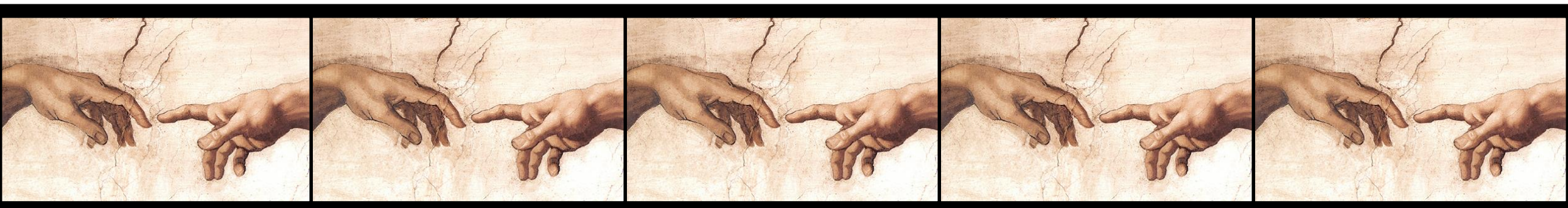




\section{ERA Propulsion Technology Tasks (Phase I)}

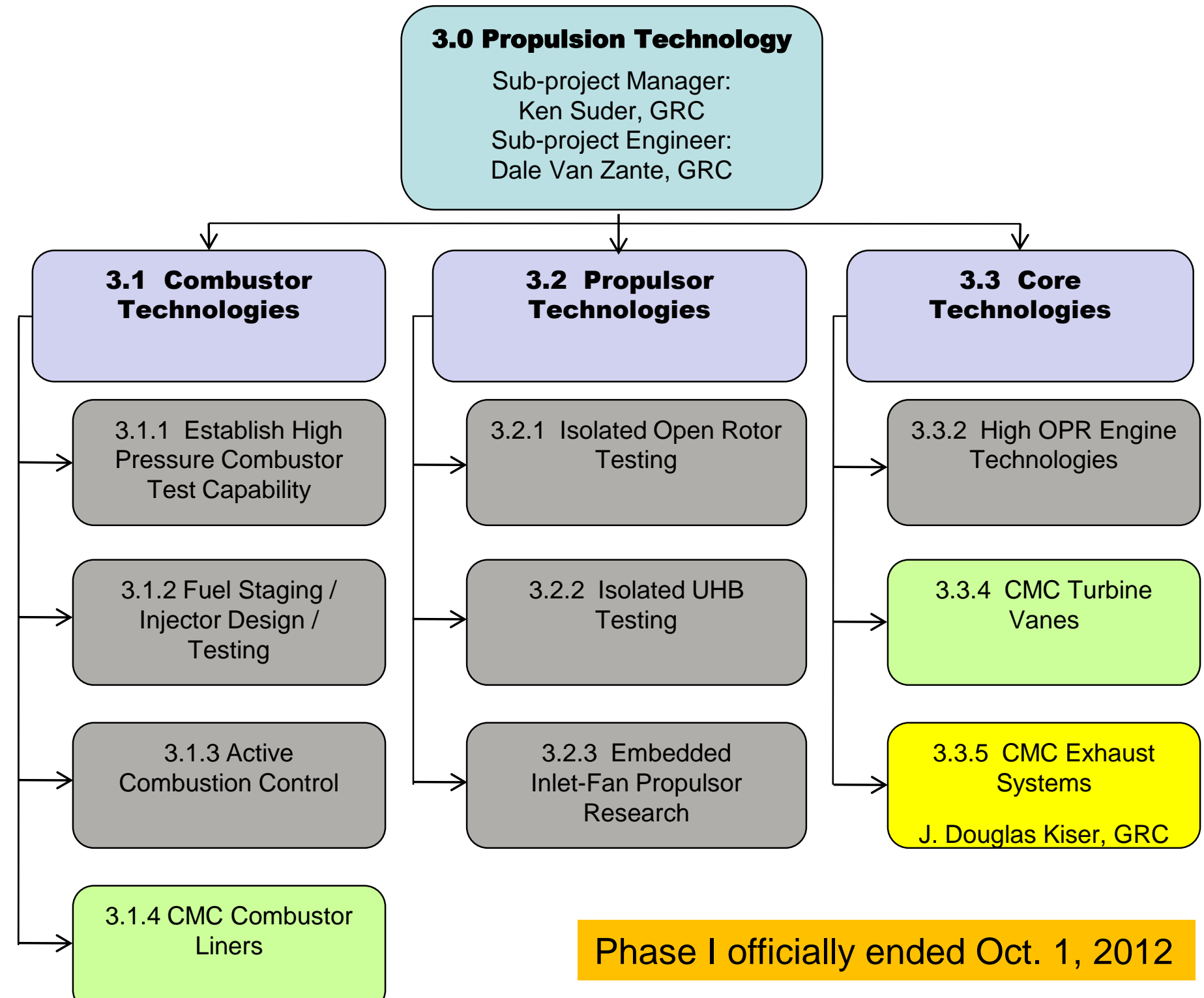




\section{COIC Processing of Oxide CMCs}

COI Ceramics, Inc.

An ATK Space Systems Affilate

\section{Oxide CMC Fabrication Process}

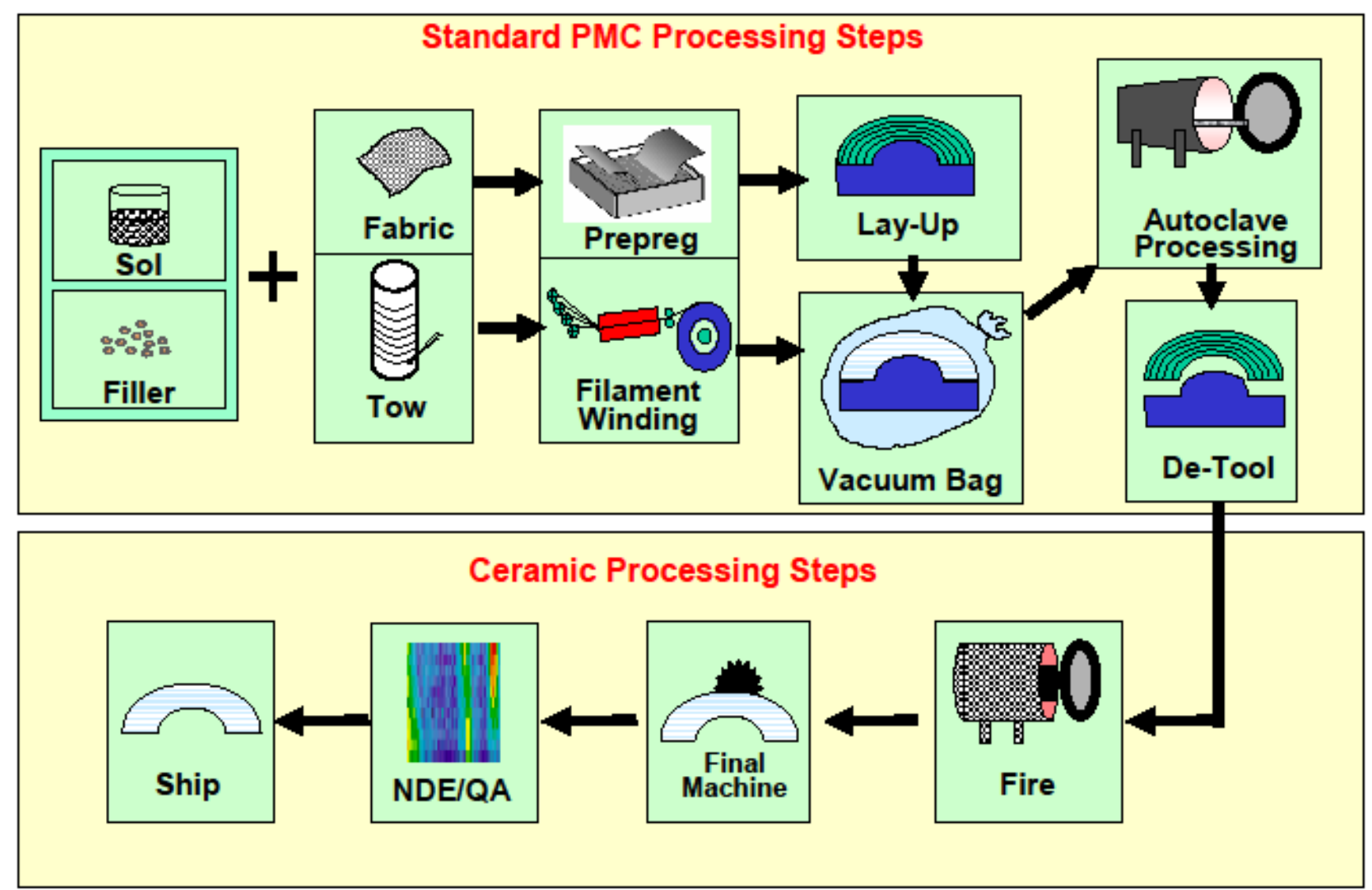

http://www.coiceramics.com/pdfs/1\%20oxide\%20process.pdf 